\title{
The aftermath of Cleveland
}

The sexual abuse of children so offends the social taboos of society that its discovery provokes strong reactions and polarisation of opinion among the public, politicians, police, and the professions. Family studies have shown that such abuse may span five generations and investigation of 'index' cases has revealed the appalling activities of child sex rings. So protean have been the overt manifestations, so secret the activities, that doctors in all branches of the profession, who treat children, have often failed to recognise the problem. We are in the 1980 s at about the same state of knowledge of sexual abuse as we were in the 1960 s as regards to the physical abuse of children. Then and now, extravagant claims have been made about the incidence of the abuse.

For those professionals who have become involved in trying to tackle the complex problems in the presence of the apparent professional apathy, determination and enthusiasm to put the needs of the children first has been interpreted as excess zeal: while those of us who have failed to recognise sexual abuse in the past have reacted defensively and sometimes with hostile disbelief. In these circumstances balanced professional judgments for recognition of sexual abuse are made more difficult.

Many manifestations of sexual abuse are covert, but much more difficult to recognise than physical abuse. This often has overt, more distinct and now well recognised patterns of bruising with definite radiological appearances. Professional reaction to physical abuse has become relatively standardised throughout the country, but the catalogue of 34 child abuse inquiries in this country bears witness that its management is fraught with human error and procedural difficulties. It was the rigid application of such procedures to the problem of child sexual abuse that provoked the crisis in Cleveland, which gave rise to the inquiry by Lord Justice Butler-Sloss, published in July this year. ${ }^{1}$

Childrens' wards with paediatrically trained staff and an appropriate environment should be the proper place for children to be examined in an understanding and non-threatening way. Childrens' wards should also be a place of safety, but with the high incidence of infectious illness among their inmates this poses additional problems.

When there has been a disclosure by a child and there are other corroborative findings of sexual abuse, urgent action may be necessary to protect the child. On the other hand, where suggestive physical signs are found without corroborative evidence a more detailed evaluation is required. Some physical signs of sexual abuse have only recently been recognised. Although individual clinicians may themselves be highly suspicious (if not certain) that abuse has taken place, it does take time for these signs to gain credence among the generality of the medical profession. It has never been good medical practice to rely on just one physical sign. The recent guide prepared by the Standing Medical Advisory Committee provides the most authoratative assessment of the physical features of sexual abuse. ${ }^{2}$ The amount of evidence that is required for clinical action involves a judgment about the balance of probabilities whereas the evidence that is required for legal action involves the findings being tested beyond reasonable doubt. What may be obvious to the clinician may still fail to meet this legal test. This fact must be borne in mind when planning the appropriate management of the child. Too often in the past social services departments have been accused of failing to act because of lack of evidence that would have enabled them to take the necessary legal action to ensure the safety of a child. Where such legal action has failed the child will remain in a damaging environment. Wynne and Hobbs have done much to draw attention to the physical signs of sexual abuse and continuing work and research is required for their evaluation. ${ }^{3}$

The problem posed by sexual abuse in Cleveland was precipitated into a crisis by the admission of a large number of children with their parents into a children's ward. The separation of the child from the family into a safe environment may secure corroborative evidence of sexual abuse by a disclosure from the child. Such a disclosure may take a considerable amount of time as the child needs to feel 'safe' to tell of his or her previous experiences. The application of a care order that relied on medical evidence alone, which could not measure up to the legal test, was bound to cause conflict. The increasing recognition of sexual abuse in Cleveland understandably resulted in the doctors and the professionals seeking more resources but there was no re-evaluation of whether the existing health care resources were being used appropriately as the report by the Lord Justice Butler-Sloss makes clear.

Interagency working through the committee structure recommended by the Department of 
Health and Social Security (DHSS) document, Working Together ${ }^{4}$ was probably more advanced in Cleveland than other health districts in this country, but it is clear that faith in these procedures to solve the problems would be entirely misplaced. The DHSS has reacted with undue haste by issuing their guidelines set out in their document, Working Together, before the recommendations of the Butler-Sloss inquiry have been studied and thought through by all the professions involved. Having delayed issuing their document for some two years, such precipitate action parallels and will accentuate the mistakes made by all the professionals in Cleveland that we are all anxious to prevent.

As different agencies have their own particular responsibilities for children it is inevitable that problems of child sexual abuse have to be resolved through interagency cooperation. The report of Lord Justice Butler-Sloss and its detailed recommendations do need to be studied further. While the recommendation to establish specialist assessment teams is welcome, further consideration must be given to the teams' responsibilities. All the available doctors in each health district who have had any experience in the management of sexual abuse will be needed to be trained and helped but whether and by whom they should become 'approved' needs to be a matter for further discussion. Consultant paediatricians in community child health who are trained in social and educational aspects of paediatrics should have a leading role and be involved in the follow up of the children and their families. It is essential that this work forms part rather than the whole of their duties. There will be severe drawbacks to the formal process of 'approval' if it is adapted from the regulations under the Mental Health Act. It has also been proposed that cases involving allegations of sexual abuse made to the police about a child or third party relating to an offence that has taken place outside the 'family' should take place without the involvement of other agencies. Though in some cases this may be acceptable, as a general rule this recommendation is fraught with difficulties.

Lord Justice Butler-Sloss and her wise assessors are to be congratulated in providing a very careful, well thought out, and balanced report where any blame is identified equally among the various individuals and agencies concerned. By taking the middle ground, Lord Justice Butler-Sloss opens herself to attack from either extreme. There can be no doubt, however, that all those involved in the crisis in Cleveland acted with the best of motives. It is the strength of this conviction to work for the best interests of the child that now has to be applied to all the agencies working with the problem in each health district to try and construct both professional and interprofessional peer review buffers so that extremes of attitude or extremes of action are prevented. There is a delicate balance to be kept in applying measures designed to protect the children, which if applied wrongly may themselves cause such devastation to the children and their families. Interagency cooperation depends more on professionalism and personality than procedures. Building up teams of senior experienced professionals in each health district who can work together, fulfil their responsibilities, and know their limitations is the only way to try to get this balance right.

\section{References}

${ }^{1}$ Butler-Sloss E. Report of the inquiry into child abuse in Cleveland 1987. London: HMSO, 1988.

2 Standing Medical Advisory Committee of the Department of Health and Social Security. Diagnosis of child sexual abuse: guidance for doctors. London: HMSO, 1988.

3 Hobbs CJ, Wynne JM. Buggery in childhood a common syndrome of child abuse. Lancet 1986;ii:792-6.

4 Department of Health and Social Security and the Welsh Office. Working together. A guide to arrangements for inter-agency co-operation for the protection of children from abuse. London: HMSO, 1988.

W J APPLEyard

Kent and Canterbury Hospital, Canterbury, Kent CT1 3NG 